\title{
Case in Point: Dilapidations
}

\section{Summary}

Title: Case in Point: Dilapidations

Publisher: RICS Books, London, UK

ISBN: 184219240X

List price: $£ 23.95$

Value for money: Poor

Jurisdiction: England and Wales
Author: Jason Hunter

Publication Date: January 2006

Details: Paperback, 180 pages

$(210 \times 119 \times 15 \mathrm{~mm})$

Best price: $£ 16.99$ at

www.constructionbooksdirect.com

The introduction to Dilapidations notes that surveyors do not need a breadth of understanding of the law of the legal profession, but in some key areas, such as landlord and tenant, they do need a similar depth of knowledge. Changing trends in clients' requirements, the introduction maintains, mean that surveyors will need to expand their legal knowledge because of the limited shelf life of that gained during training, college or university. This book seeks to identify a similarity of approach while recognising that past decisions may be of little value because of the differences between the location, age, state, lease conditions and time of the decision on the facts of a case and those that may apply to the matter being considered.

The book is arranged in the manner that the author considers a surveyor should use to approach a dilapidation problem; starting with the lease then looking at limitations to claims, considering cases that determine whether the lease covenants have been broken, then looking at the extent of any repair required and finally considering the remedies of the landlord. The book is a mixture of general guidance and related case summaries.

The layout of this book is a muddle. Each section or subsection starts with general text that sets out the main context of the section, for example, litigation costs and fees, and then sets out case summaries that touch on the subject. First, the summary of the case is often of no value because it is so brief (for example, in one case the court made orders for costs based on the issues in dispute and which party had been successful in particular respects (Johnson Estates)). Secondly, the division between case summary and text is a grey line across the page. This layout does no service to the reader because it divides the explanations into chunks that, in many places, do not stand alone. In places the continuation of the text 
makes no sense unless one works back within the book to find the previous text to which it refers. Then one comes to matters of style. To understand complex subjects the writing needs to be simple and lucid. In this case the reader is challenged not only by the subject but also by the complexity of the sentence structure used.

To call a book by a subject title sets a high standard for the content. Such a book must at least be the equal of those other books that deal with the same subject matter. It is unusual in a book review to quote another book, but as the text of this book frequently defers to and quotes Dowding and Reynolds (2004) it is difficult to avoid comparing the two books. While the 3rd edition of Dowding and Reynolds (2004) costs a lot more $(£ 175)$ it is far more comprehensive and much better argued. It is also frequently cited in court decisions. This reviewer suggests that if surveyors need in-depth knowledge then that dilapidations book is a better resource.

Malcolm Hollis

Managing Editor

\section{References}

Johnson Estates 2001 Ltd v Secretary of State for the Environment, Transport and the Regions.

Dowding, N. and Reynolds, K. (2004) Dilapidations: The Modern Law and Practice, Sweet and Maxwell, London, UK (supplemented 2005). 